\title{
Development of T-cell large granular lymphocytic leukemia in the course of B-cell chronic lymphocytic leukemia with a causal relationship inferred from a flow cytometric analysis of the bone marrow aspirate
}

Andrew M. Plata ${ }^{1}$, James N. Frame ${ }^{2}$, Jeremy Stuelpnagel ${ }^{3}$, Tajana Juranovic ${ }^{4}$, Oscar C. Estalilla ${ }^{5}$ and Tomislav M. Jelic ${ }^{5^{*}}$

${ }^{*}$ Correspondence: tjelic@suddenlink.net

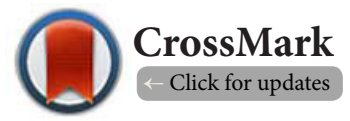

\author{
${ }^{1}$ Autonomous University of Guadalajara, Mexico. \\ 2David Lee Cancer Center, Charleston WV, 25304, USA. \\ ${ }^{3}$ Department of Pathology, West Virginia University, Morgantown, WV 26506, USA. \\ ${ }^{4}$ Clinical Hospital Centre Rijeka, University of Rijeka, Rijeka, Croatia. \\ ${ }^{5}$ Department of Pathology and Laboratory Medicine, Charleston Area Medical Center, 3200 MacCorkle Ave, Charleston, WV 25304, \\ USA.
}

\begin{abstract}
Background: B-cell chronic lymphocytic leukemia is the most frequent leukemia in the western world while T-cell large granular lymphocytic leukemia with cytotoxic $\left(\mathrm{CD} 8^{+} / \mathrm{CD}^{+} \mathrm{CD} 4^{-}\right)$immunophenotype is rare. There is much ongoing interest regarding the interaction between $\mathrm{T}$ cells and $\mathrm{B}$-cell chronic lymphocytic leukemia cells.
\end{abstract}

Methods: Peripheral blood and bone marrow samples from a 72 year-old-man with a simultaneous presence of these two types of leukemia were examined and analyzed by conventional morphology, flow cytometry, immunohistochemistry, chromosomal study, and molecular studies.

Results: Flow cytometric analysis of the bone marrow aspirate documented B-cell chronic lymphocytic leukemia, $\mathrm{CD}^{+} \mathrm{CD}^{+} \mathrm{T}$-cell large granular lymphocytic leukemia, and demonstrated the presence of three subpopulations of $\mathrm{CD}^{+}$T-cells with transitional immunophenotypes between that of benign and malignant $\mathrm{CD} 8^{+}$T-cells.

Conclusions: We report the first case of simultaneous presence of B-cell chronic lymphocytic leukemia and $\mathrm{T}$-cell large granular lymphocytic leukemia with cytotoxic $\left(\mathrm{CD} 8^{+} / \mathrm{CD}^{+} / \mathrm{CD} 4^{-}\right)$immunophenotype. The simultaneous presence of malignant $\mathrm{CD} 8^{+} \mathrm{CD}^{+} \mathrm{T}$-cell large granular lymphocytes together with the three immunophenotypically different subpopulations of $\mathrm{CD} 3^{+} \mathrm{CD} 8^{+} \mathrm{T}$-cells indicated an ongoing stepwise malignant transformation of large granular lymphocytes late in the 9-year-course of B-cell chronic lymphocytic leukemia. We propose that chronic antigenic stimulation by B-cell chronic lymphocytic leukemia cells and immune deficiency inherent to B-cell chronic lymphocytic leukemia additionally augmented by treatment with fludarabine, may cause development of T-cell large granular lymphocytic leukemia.

Keywords: B-cell chronic lymphocytic leukemia, T-cell large granular lymphocytic leukemia, bone marrow, cytotoxic

\section{Introduction}

B-cell chronic lymphocytic leukemia (B-CLL) is a neoplasm of mature small B lymphocytes (Figure 1) with an abnormally long life span in which the malignant lymphocytes infiltrate bone marrow, peripheral blood, lymph nodes and the spleen. T-cell large granular lymphocytic leukemia with cytotoxic (CD8 ${ }^{+} /$ $\left.\mathrm{CD}^{+} / \mathrm{CD}^{-}\right)$immunophenotype (T-LGL leukemia) is a neoplastic expansion of suppressor/cytotoxic large granular lymphocytes (T-LGL) that also involve peripheral blood, bone marrow, the spleen, and liver. Large granular lymphocytic leukemia is the 
Plata et al. Pathology Discovery 2015,

clonal expansion of either CD8 positive cytotoxic T-cells $(80 \%)$ or natural killer cells $(20 \%)$. Normal number of LGL (morphology is depicted in Figure 1) in the peripheral blood is 100 to $300 \mathrm{LGL} / \mathrm{microliter}(\mu \mathrm{L})\left(0.1-0.3 \times 10^{9} \mathrm{LGL} / \mathrm{L}\right)$ or $5 \%$ to $15 \%$ of peripheral blood lymphocytes. According to the immunophenotype, $L G L$ are divided in two types of cells: CD8 and CD3 positive suppressor/cytotoxic T-cells and natural killer cells (CD3 negative, CD16 positive LGL). Malignant T-cells exhibit aberrant expressions of one or several pan T-cell

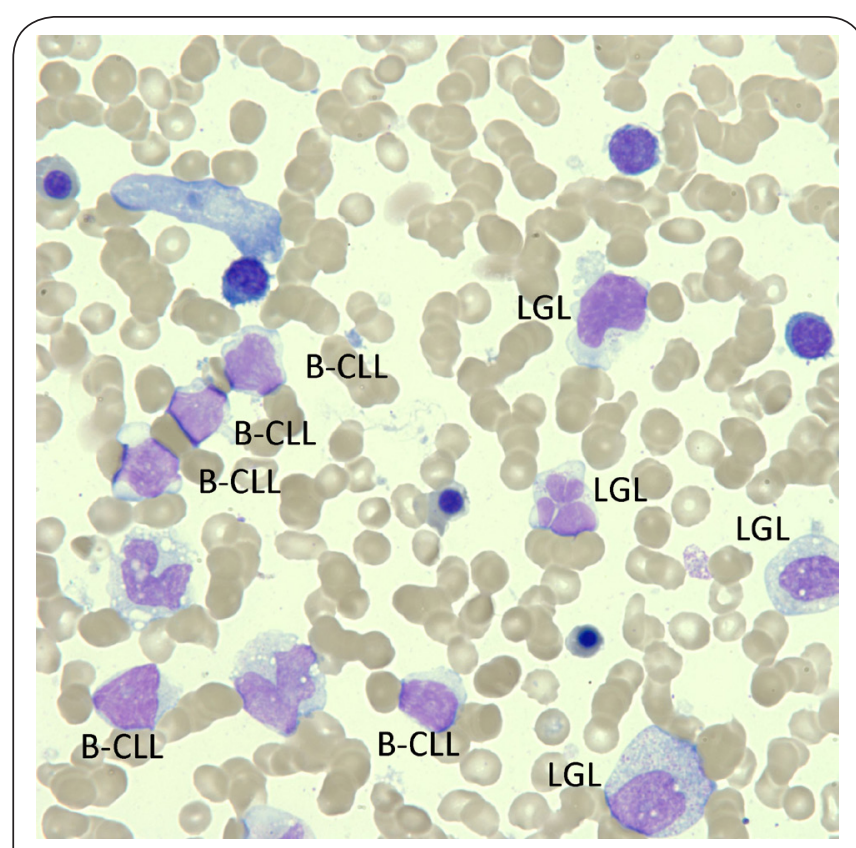

Figure 1. Bone marrow aspirate smear Wright-Giemsa stain, original magnification 1000 (oil immersion) showing simultaneous presence of B-cell chronic lymphocytic leukemia cells (B-CLL) and large granular lymphocytic leukemia cells (LGL). markers (Figure 2), are resistant to apoptosis, and harbor the $T$-cell receptor gene rearrangement. The main function of $L G L s$ is to kill microorganisms and infected cells. Their number is increased in a peripheral blood as a reaction to viral and fungal infections or autoimmune diseases. It is presumed that the T-LGL reactive/persistent lymphocytosis, which usually occurs in autoimmune diseases, is a precursor of $\mathrm{CD} 8^{+} \mathrm{T}$-cell large granular lymphocytic leukemia [1]. Both the T-LGL reactive/ persistent lymphocytosis and T-LGL leukemia are associated with autoimmune diseases [2]. Accumulation of malignant cells in B-CLL is primarily due to alterations in the regulation of apoptosis and not to unregulated excessive proliferation $[3,4]$. For this reason, $B-C L L$ is an indolent disease but at the same time incurable. In T-LGL leukemia the number of large granular lymphocytes in the peripheral blood is increased, typically from 2,000 to 20,000 cells/ $\mu \mathrm{L}$. Although T-LGL leukemia is usually an indolent disease with median survival more than 10 years [5], patients who develop cytopenia usually require treatment.

\section{Case presentation}

We have followed and treated a man who at age 62 presented with enlarged lymph nodes and was diagnosed with B-CLL. When 14 months later the number of leukocytes increased to $128,000 / \mu \mathrm{L}$ and staging showed Rai 4 , he received 5 cycles of FCR (fludarabine, cytoxan, rituxan). A complete clinical remission was achieved, but seven years later large granular lymphocytosis ( $56 \% \mathrm{LGL} 2688 \mathrm{LGL} / \mu \mathrm{L}$ ) developed. At the age of 72 years with a 9-year history of B-CLL and a 2-year history of large granular cell lymphocytosis, he presented with marked neutropenia (64 neutrophils $/ \mu \mathrm{L}$ ) and mild thrombocytopenia $(112 \mathrm{~K} / \mu \mathrm{L})$. A manual differential count showed $1 \%$ neutrophils, $71 \%$ small lymphocytes, $22 \%$ large granular lymphocytes, and $6 \%$ monocytes. Light microscopic examination demonstrated the simultaneous presence of B-CLL cells and LGL

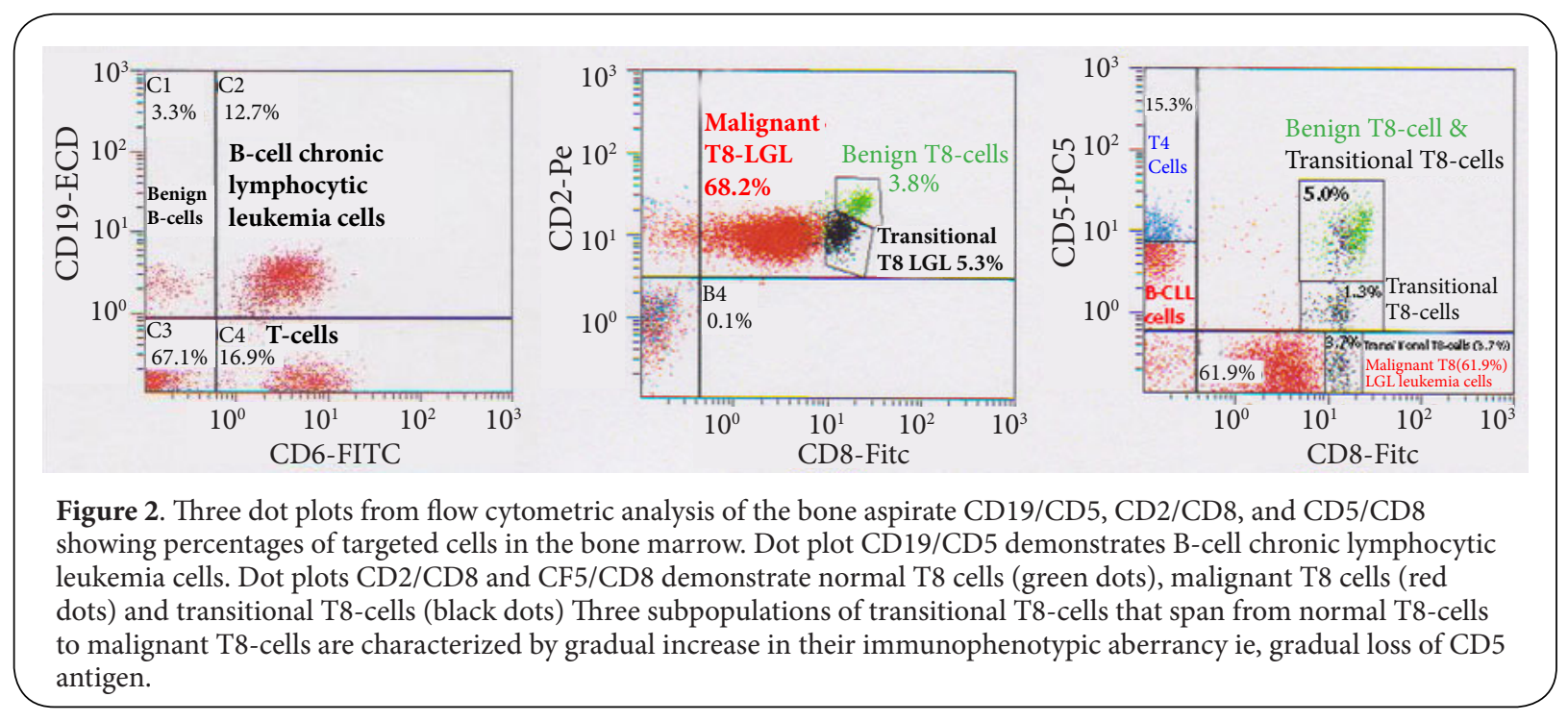


leukemia cells in both, blood and bone marrow (Figure 1). Flow cytometric analysis of the bone marrow aspirate documented that lymphocytes comprised about $72 \%$ of marrow cells. The B-CLL cells that expressed CD19 and CD5 (Figure 2) comprised $12.7 \%$ of lymphoid cells, i.e., about $9.1 \%$ of marrow cells. Benign, polyclonal B-cells (kappa: lambda $=1.1$ ) comprised $3.3 \%$ of lymphoid cells, i.e., about $2.4 \%$ of marrow cells. The $\mathrm{CD}^{+}$T-large granular lymphocytic leukemia cells comprised $61.9 \%$ to $68.2 \% 68$ of lymphoid cells, i.e., about $47 \%$ of marrow cells (Figure 2 ). Benign $\mathrm{CD} 8^{+} \mathrm{T}$-cells (T8-cells) comprised $3.8 \%$ of lymphoid cells, i.e., about $2.7 \%$ of marrow cells (Figure 2). Malignant CD8 ${ }^{+} \mathrm{T}$-cells showed aberrant immunophenotype as shown in Figure 2; the CD5 was lost (absent) while expression of CD2, CD7, and CD8 was dimmer than their expression in normal T8-cells. In Figure 2, there is a small population of transitional T8-cells (black dots) that are between benign T8-cells (green dots) and malignant T8-cells (red dots). They comprise $5.3 \%$ of lymphoid cells, about 3.8\% of marrow cells, and $7 \%$ of all T8-cells. These transitional cells express CD2 and CD8 less strongly than normal (benign) T8-cells, but they do express CD8 stronger than malignant T8-cells. Dot plot CD5/CD8 (Figure 2) has divided these transitional T8-cells into three subgroups. The T8-cells of the first subgroup express CD5 as bright as benign T8-cells but with slightly less bright expression of CD8 and there is a trail of expression of CD5 that bridges to dim expression of CD5 of the second subgroup. The first subgroup of transitional T8 cells comprises about $2 \%$ of lymphoid cells and about $1.4 \%$ of marrow cells. Cells of the second subgroup of transitional T8-cells dimly express CD5. They comprise $1.3 \%$ of lymphoid cells and about $0.9 \%$ of marrow cells. Cells of the third subgroup of transitional T8-cells do not express CD5 at all. They comprise $3.7 \%$ of lymphoid cells and about $2.7 \%$ of marrow cells. These three small populations of T8 cells represent transitional cells between normal T8-cells and malignant $\mathrm{CD}^{+}{ }^{-} \mathrm{T}-$ LGL leukemia cells, and we presume that they are oligoclonal $\mathrm{CD}^{+} \mathrm{T}$-cell large granular lymphocytes. Their number is too small to be detected by molecular study. Polymerase chain reaction demonstrated clonal T-cell receptor gamma gene rearrangement. A FISH study demonstrated deletion of DLEU 1, DLEU2 on chromosome 13 at q14, which portends a good prognosis (median survival 133 months) to patients with Bcell chronic lymphocytic leukemia. The chromosomal study demonstrated a normal male karyotype. During therapy, the patient developed severe pancytoenia, sepsis and expired.

\section{Discussion and conclusion}

The B-CLL causes various acquired T-cell abnormalities, including an increased number of T8-cells and thus a reversed T4/T8 ratio, as well as expansions of clonal and oligoclonal suppressor/cytotoxic CD8 ${ }^{+} \mathrm{T}$-cells [6]. The $\mathrm{CD} 3^{+} \mathrm{CD} 8^{+} \mathrm{T}$-LGL leukemia clone does not appear to be entirely autonomous, and it is possible that T-LGL leukemia is a deregulated reaction to viral infections or self antigens [7]. Malignant lymphocytes of B-CLL can present antigens and also by them be a chronic antigenic stimulus. It is thus entirely plausible that B-CLL could cause T-LGL leukemia. Flow cytometric analysis of our case demonstrated B-CLL cells and simultaneously T-LGL leukemic cells. However, it also revealed three sub populations of T8 cells with immune phenotype between normal T8 cells and malignant CD8 ${ }^{+} \mathrm{T}-\mathrm{LGL}$ leukemic cells. These transitional cells exhibit expression of $C D 5$ in a continuum ranging from bright to $\operatorname{dim}$ and to nil, denoting the degree of immunophenotypic aberrancy. We regard the immunophenotypically transitional cells as the immunophenotypic counterpart of oligoclonal $C D 8^{+}$ T-cells. The presence in our patient of immunophenotypycally benign T8-cells, transitional T8-cells, and malignant T8-cells conforms to the accepted terms of expansion of normal, oligoconal, and clonal T-cells in B-cell chronic lymphocytic leukemia [6]. Existence of the three subtypes of transitional T8-cells suggests that due to the presence of B-CLL, process of the neoplastic transformation of normal T8-cells to leukemic cells is ongoing and gradually progressing, and that simultaneous occurrence of these two malignancies is not coincidental but causally related. We report to the best of our knowledge the first case of immunophenotypically documented simultaneous occurrence of $\mathrm{B}-\mathrm{CLL}$ and $\mathrm{CD} 3^{+} \mathrm{CD} 8^{+} \mathrm{T}-\mathrm{LGL}$ leukemia. In a case reported 15 years ago of an 84 year-old-man with B-CLL and T-cell large granular lymphocytic leukemia the status of CD8 was not reported [8].

On the basis of flow cytometric findings of the three subpopulatons of transitional cells indicating stepwise malignant progression of $\mathrm{CD} 8^{+} \mathrm{T}$-cells and temporal relation between the two diseases, we propose that chronic antigenic stimulation by B-CLL cells and immune deficiency inherent to B-CLL and augmented by treatment with fludarabine, may cause development of $C D 8^{+} \mathrm{T}$-cell large granular lymphocytic leukemia. This is in agreement with authors who observed a development of peripheral T-cell lymphomas with cytotoxic phenotype in the patients with B-CLL $[9,10]$.

\section{Competing interests}

The authors declare that they have no competing interests.

\section{Authors' contributions}

\begin{tabular}{|l|c|c|c|c|c|c|}
\hline Authors' contributions & AMP & JNF & JS & TJ & OCE & TMJ \\
\hline Research concept and design & $\checkmark$ & $\checkmark$ & $\checkmark$ & $\checkmark$ & $\checkmark$ & $\checkmark$ \\
\hline Collection and/or assembly of data & -- & $\checkmark$ & $\checkmark$ & $\checkmark$ & -- & -- \\
\hline Data analysis and interpretation & $\checkmark$ & $\checkmark$ & $\checkmark$ & $\checkmark$ & $\checkmark$ & $\checkmark$ \\
\hline Writing the article & $\checkmark$ & $\checkmark$ & $\checkmark$ & $\checkmark$ & $\checkmark$ & $\checkmark$ \\
\hline Critical revision of the article & $\checkmark$ & -- & -- & -- & $\checkmark$ & $\checkmark$ \\
\hline Final approval of article & $\checkmark$ & $\checkmark$ & $\checkmark$ & $\checkmark$ & $\checkmark$ & $\checkmark$ \\
\hline Statistical analysis & $\checkmark$ & -- & -- & $\checkmark$ & -- & -- \\
\hline
\end{tabular}

Acknowledgement

We are greatly indebted to the high technical expertise of Mrs. Josephine C. Roque and Ms. Jessica L. Bowyer at the Flow Cytometry Laboratory CAMC, Charleston WV, USA. 
Plata et al. Pathology Discovery 2015,

Publication history

Editor: Mark Alexander Catherwood, Belfast City Hospita, UK. EIC: Markus H. Frank, Harvard Medical School, USA.

Received: 08-Mar-2015 Final Revised: 08-Apr-2015

Accepted: 14-Apr-2015 Published: 20-Apr-2015

\section{References}

1. Dhodapkar MV, Li CY, Lust JA, Tefferi A and Phyliky RL. Clinical spectrum of clonal proliferations of T-large granular lymphocytes: a T-cell clonopathy of undetermined significance? Blood. 1994; 84:1620-7. | Article | PubMed

2. O'Malley DP. T-cell large granular leukemia and related proliferations. Am J Clin Pathol. 2007; 127:850-9. | Article | PubMed

3. Gottardi D, Alfarano A, De Leo AM, Stacchini A, Bergui L and CaligarisCappio F. Defective apoptosis due to $\mathrm{Bcl}-2$ overexpression may explain why B-CLL cells accumulate in G0. Curr Top Microbiol Immunol. 1995; 194:307-12. | Article | PubMed

4. Hanada M, Delia D, Aiello A, Stadtmauer E and Reed JC. bcl-2 gene hypomethylation and high-level expression in B-cell chronic lymphocytic leukemia. Blood. 1993; 82:1820-8. | Article I PubMed

5. Zhang D and Loughran TP, Jr. Large granular lymphocytic leukemia: molecular pathogenesis, clinical manifestations, and treatment. Hematology Am Soc Hematol Educ Program. 2012; 2012:652-9. I Article I PubMed

6. Goolsby $\mathrm{Cl}$, Kuchnio M, Finn, W and Peterson LoAnn. Expansions of clonal and oligoclonal T cells in B-cell chronic lymphocytic leukemia are primarily restricted to the $\mathrm{CD}^{+} \mathrm{CD}^{+} \mathrm{T}$-cell population. Cytometry. 2000; 42:188-195. | Article | PubMed

7. O’Keefe CL, Plasilova M, Wlodarski M, Risitano AM, Rodriguez AR, Howe E, Young NS, Hsi E and Maciejewski JP. Molecular analysis of TCR clonotypes in LGL: a clonal model for polyclonal responses. J Immunol. 2004; 172:1960-9. I Article I PubMed

8. Lesesve JF, Feugier P, Lamy T, Bene MC, Gregoire MJ, Lenormand B and Loughran T. Association of B-chronic lymphocytic leukaemia and T-large granular lymphocyte leukaemia. Clin Lab Haematol. 2000; 22:121-2. | Article | PubMed

9. Boyer DF, Lindeman NI, Harris NL and Ferry JA. Peripheral T-cell lymphomas with cytotoxic phenotype in patients with chronic lymphocytic leukemia/small lymphocytic lymphoma. Am J Surg Pathol. 2014; 38:279-88. | Article | PubMed

10. Martinez A, Pittaluga S, Villamor N, Colomer D, Rozman M, Raffeld $\mathrm{M}$, Montserrat E, Campo E and Jaffe ES. Clonal T-cell populations and increased risk for cytotoxic T-cell lymphomas in B-CLL patients: clinicopathologic observations and molecular analysis. Am J Surg Pathol. 2004; 28:849-58. | Article | PubMed

\section{Citation:}

Plata AM, Frame JN, Stuelpnagel J, Juranovic T, Estalilla OC and Jelic TM. Development of T-cell large granular lymphocytic leukemia in the course of B-cell chronic lymphocytic leukemia with a causal relationship inferred from a flow cytometric analysis of the bone marrow aspirate. Pathol Discov. 2015; 3:4. http://dx.doi.org/10.7243/2052-7896-3-4 